\title{
Assessment of the gonadotrophin-gonadal axis in androgen insensitivity syndrome
}

\author{
S F Ahmed, A Cheng, I A Hughes
}

\begin{abstract}
Objective-To study the value of measuring serum luteinising hormone (LH), follicle stimulating hormone (FSH), testosterone, and dihydrotestosterone (DHT) in androgen insensitivity syndrome (AIS). Design-Retrospective study of patients on a nationwide register of AIS.

Patients-Sixty one cases of AIS with androgen receptor (AR) dysfunction (abnormalities of the AR gene and/or abnormal AR binding) were divided into three age groups: infants, < 1 year old; children, 1-13 years old; and postpubertal, > 13 years old.
\end{abstract}

Measurements-Age, dose of human chorionic gonadotrophin (hCG) stimulation, pre-hCG and post-hCG serum testosterone values, serum DHT values, and serum LH and FSH values before and after $\mathrm{LH}$ releasing hormone (LHRH) stimulation. Results-In 23 of 30 infants testosterone was within age related reference ranges; six were above this range. The median testosterone rise following variable dosage of hCG was 9.5 times the basal value. The increment was not related to the hCG dose, age, or basal concentration of testosterone. The median basal and stimulated testosterone:DHT ratios were 2.5 and 6.1 , respectively. The median increment in DHT was 2.2-fold. Seventeen of 18 FSH and 11 of 19 LH measurements were within age related ranges in infants; in seven patients $L H$ values were above the range. LHRH stimulation performed in 39 patients showed an exaggerated LH in all age groups. The FSH response was not exaggerated in children.

Conclusion-Although a positive hCG test excludes biosynthetic defects of testosterone, an inadequate response does not exclude AIS. Basal LH and testosterone may not be raised during early infancy. An LHRH stimulation test might be useful for evaluating cases of suspected AIS presenting in mid-childhood.

(Arch Dis Child 1999;80:324-329)

Keywords: androgen insensitivity syndrome; Leydig cells; human chorionic gonadotrophin stimulation

Department of Paediatrics, Princess Margaret Hospital, Lai Chi Kok, Kowloon, Hong Kong

A Cheng

Correspondence to: Dr Ahmed.

email: sfa21@cam.ac.uk

Accepted 19 October 1998 (AR) gene. The clinical manifestations androgen resistance vary from external genitalia that are completely female (complete AIS)
The androgen insensitivity syndromes (AIS) arise from target tissue resistance to androgen action caused by molecular abnormalities in the $\mathrm{X}$ chromosome linked androgen receptor to degrees of partial masculinisation (partial AIS). These syndromes are probably the most common identifiable cause of male undermasculinisation and consequent genital ambiguity at birth, but can be confused with other causes of under-masculinisation if not investigated adequately. ${ }^{1}$ Diagnostic schema for studying possible cases of AIS have been proposed, ${ }^{1-3}$ but diagnosis in the absence of binding studies of AR and mutational analysis of the gene encoding AR remains difficult. Age related reference ranges for serum gonadotrophins and testosterone are available $e^{4-6}$ and, although these measurements are often performed at the time of presentation, there is some uncertainty regarding the value of these tests. Postpubertal patients with complete AIS, who have testes in situ, have raised serum concentrations of luteinising hormone (LH), and normal to slightly raised concentrations of follicle stimulating hormone (FSH) and testosterone relative to normal boys. ${ }^{78}$ In contrast, affected prepubertal children have LH and testosterone concentrations in the normal range. ${ }^{8}$ However, studies in infants and neonates with AIS are restricted to a few case reports, ${ }^{9-11}$ where it is debatable whether LH and testosterone concentrations were abnormal, considering the variable pattern of these hormones in normal infants. ${ }^{5}$ The stimulation of testosterone production by human chorionic gonadotrophin (hCG) has traditionally been performed to detect functioning testicular tissue, ${ }^{12-14}$ as well as to pinpoint abnormalities in testosterone biosynthesis. ${ }^{15}{ }^{16}$ Case reports as well as a recent series of nine cases of AIS show that testosterone increases significantly after hCG stimulation..$^{9-12}$ Therefore, we have collected information about the gonadotrophingonadal axis in a group of patients with complete and partial AIS with abnormal AR binding and/or mutations in the AR gene. This information should improve the interpretation of investigations performed commonly in cases of male under-masculinisation.

\section{Patients and methods}

The UK database of ambiguous genitalia and intersex disorders, which is held at Cambridge, has over 700 separate entries. Among these, there are 255 cases of AIS diagnosed by clinicians nationwide, of whom phenotype is compatible with complete AIS in 102 and partial AIS in 153. We obtained clinical information and results of the investigations performed. For our study, patients were only selected if there was evidence of AR dysfunction (AR +ve) - that is, abnormalities on mutational analysis of the gene encoding $\mathrm{AR}$ and/or 

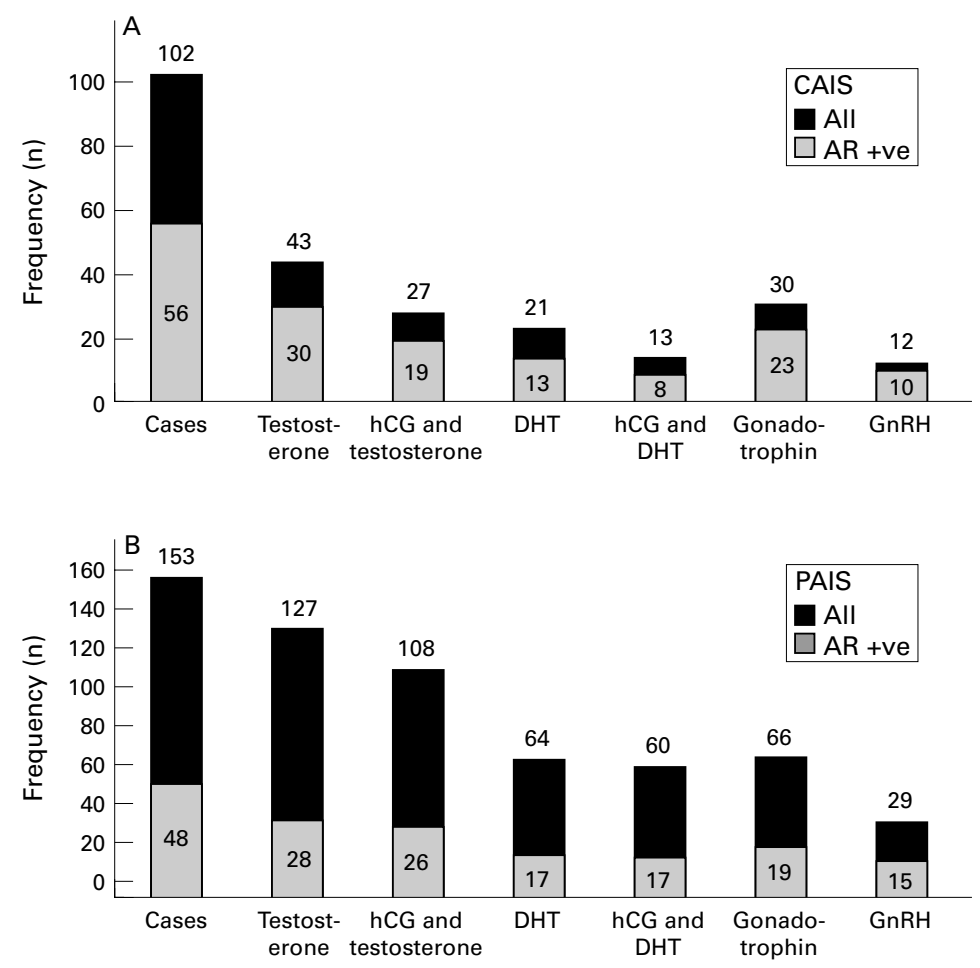

Figure 1 Complete AIS (CAIS) and partial AIS (PAIS) cases in the database at the time of our study and the subset of cases with abnormalities of AR binding or AR gene mutations ( $A R+v e$; shaded bars) where information regarding basal plasma testosterone, hCG stimulation test, basal serum gonadotrophins (LH and FSH), and gonadotrophin releasing hormone stimulation test $(\mathrm{GnRH})$ were available.

abnormal results from an AR binding assay, as described previously. ${ }^{17}{ }^{18}$ For the analysis, these cases of complete AIS and partial AIS were considered as one group, but were divided into three subsets according to age as follows: infants, less than 1 year old; children, 1-13 years old; postpubertal, more than 13 years old. Cases where investigations were performed after gonadectomy were excluded. Data analysed included age at investigation, gestation, dose of hCG stimulation, dose of LH releasing hormone (LHRH), serum testosterone (nmol/1), dihydrotestosterone (DHT; $\mathrm{nmol} / \mathrm{l}), \mathrm{LH}(\mathrm{U} / \mathrm{l})$, and $\mathrm{FSH}(\mathrm{U} / \mathrm{l})$. As shown in fig 1 , the results of these tests were available in a variable number of cases of AIS. Hormonal analyses were performed by standard immunoassays at endocrine laboratories participating in a national external quality control service (UKNEQAS). The interassay variability ranges between $10 \%$ and $20 \%$ (by courtesy of UKNEQAS). Assay results are presented as medians and 90th centiles, and intergroup comparison was performed by the Wilcoxon signed rank (WSR) test. Chi-squared analysis was used to evaluate any relation between clinical features and the hCG test. Testosterone, $\mathrm{LH}$, and $\mathrm{FSH}$ values were compared with those described in normal children in the literature. ${ }^{4}$

\section{Results}

TESTOSTERONE AND hCG STIMULATION

Basal testosterone concentrations were available in $58 \mathrm{AR}+\mathrm{ve}$ cases and were high in infancy, declining to low during childhood,
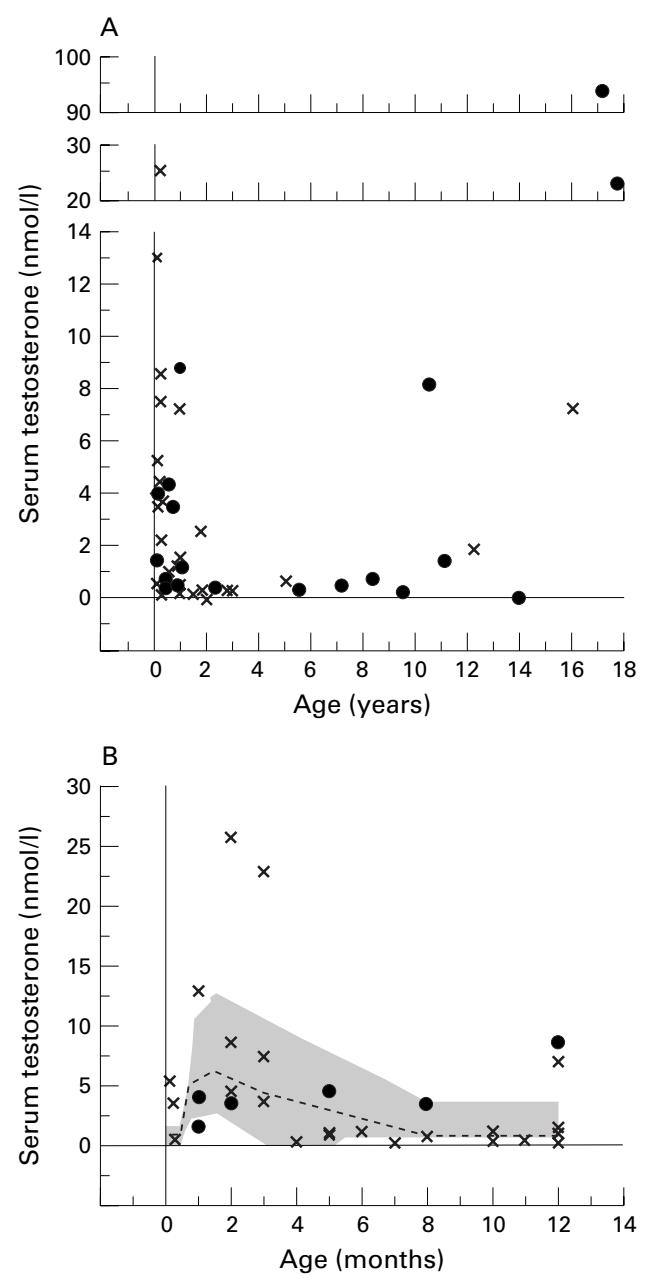

Figure 2 Basal plasma testosterone concentrations in AIS. (A) Total AR +ve cases of AIS (the high testosterone concentrations in three patients are plotted separately). (B) All AR +ve cases less than 1 year old. Closed circles and crosses represent cases of complete AIS and partial AIS, respectively. The shaded area represents the normal reference range.

before rising again postpubertally (fig 2A). There was considerable variation in testosterone concentrations over the 1st year consistent with the changes described in healthy boys over the first 6 months of life (fig 2B). Twenty three of 30 measurements were within the historical reference range, whereas seven of 30 were above this range.

There was considerable variation in the regimen of hCG stimulation used, although 1000$2000 \mathrm{U}$ for three consecutive days accounted for $59 \%$ of all the tests (fig 3). Results of hCG stimulation were available for 45 patients with AR dysfunction (fig 1) and the median (10-90th centile) rise in testosterone on hCG stimulation in these cases was 9.5 (1.8-38) times the basal concentration. The testosterone increment was not related to the total hCG dose, the age at which the test was performed, or the basal concentration of testosterone. The actual concentrations of testosterone are shown in fig 4 . Twenty three hCG stimulation tests were performed in infants and 21 were performed in older children. The median (1090th centile) basal and peak testosterone values were $2.3 \mathrm{nmol} / 1 \quad(0.5-9.5)$ and $14.8 \mathrm{nmol} / 1$ 


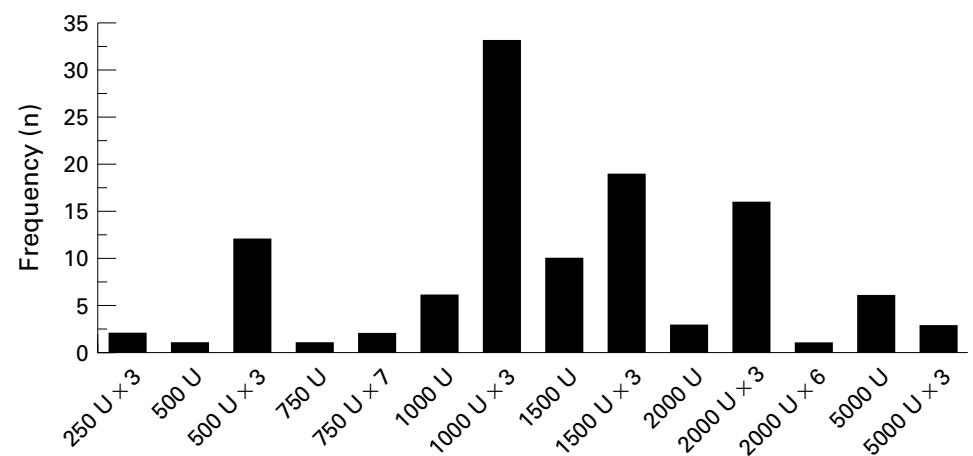

Figure 3 Frequency ( $n$ ) of different regimens of HCG stimulation tests used in all cases of suspected AIS.

(3.8-34.4), respectively, in the infants, and $0.8 \mathrm{nmol} / 1 \quad(0.2-5.1)$ and $10.6 \mathrm{nmol} / 1$ (3.921.7), respectively, in the older children. There was no significant difference between the basal or peak values in the infants and older children. Among the cohort which had an hCG stimulation test, there were 12 patients who had testes that were bilaterally descended and nine where they were bilaterally intra-abdominal; the remainder had a combination of these features. The median (10-90th centile) testosterone increment on hCG stimulation was 5 (1.788.9) times the basal value and 9.5 (1.9-53) times the basal value (not significant) in the two groups, respectively.

DHT AND hCG STIMULATION

Baseline and post-hCG stimulation DHT concentrationss were available in 30 and $23 \mathrm{AR}$ +ve cases of AIS, respectively (fig 1). In the latter group of cases mean (10-90th centile) increment in testosterone on hCG stimulation was 5.5-fold (2-63) and the median (10-90th centile) increment in DHT was 2.2-fold (1.313.2). The dose of hCG used was known in 21 of 23 cases; there was no relation between the dose and the rise in testosterone or DHT. The median (10-90th centile) basal testosterone:DHT (T:DHT) ratio at $2.5(0.6-11)$ was

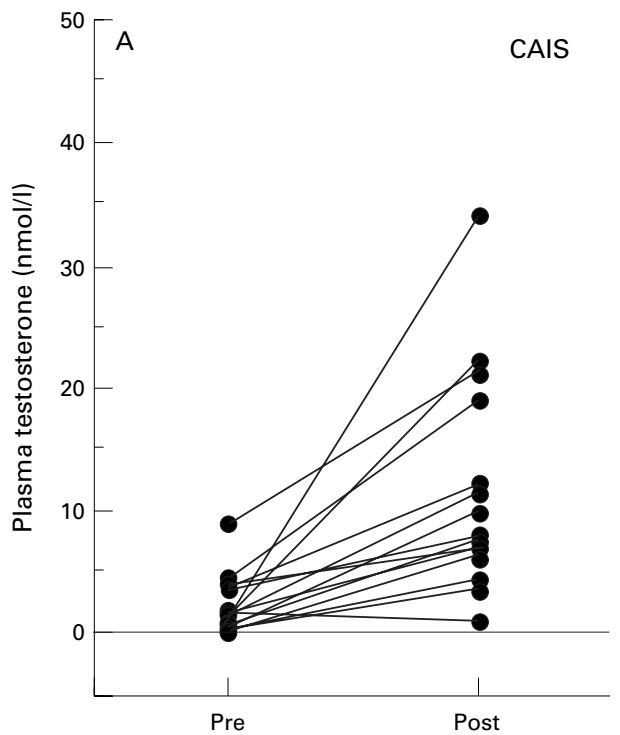

lower than the median (10-90th centile) stimulated T:DHT ratio of 6.1 (1.3-17; $\mathrm{p}=0.0009)$. Figure 5 shows the variation in the T:DHT ratio in children under the age of 3 years $(n=20)$. Following hCG stimulation an age dependent rise in the ratio was noticed over the 1 st year of life.

GONADOTROPHINS AND LHRH STIMULATION

Basal LH and FSH values were available for 42 AR +ve cases of AIS (fig 1), which showed that age dependent variation was high in the 1 st few months of life, reaching a nadir in childhood, before rising again (fig 6). Seventeen of 18 FSH measurements and 11 of 19 LH measurements performed in the 1st year of life were within age related ranges (fig 7), and seven $\mathrm{LH}$ measurements were above the reference range. The median basal and stimulated concentrations of LH and FSH are shown in table 1. Exaggerated responses to LHRH stimulation were seen in the infants and the postpubertal group. Although the peak FSH value in the children was not exaggerated, the median peak $\mathrm{LH}$ value was six times higher than basal values.

\section{Discussion}

The diagnosis of androgen insensitivity can be difficult to establish but is facilitated by a family history showing $\mathrm{X}$ linked inheritance, a comprehensive clinical examination, and investigations to exclude other causes of male under-masculinisation. Published studies of biochemical investigations, including gonadotrophin and androgen values, have concentrated on older children and adults; most of these studies lack information about AR binding and mutational analysis of the AR gene. Serum gonadotrophin as well as testosterone concentrations are often measured when AIS is suspected; however, adequate interpretation of the results has been restricted because of different opinions based on personal observations as well as on case studies. ${ }^{9-11} 1920$ Therefore, we

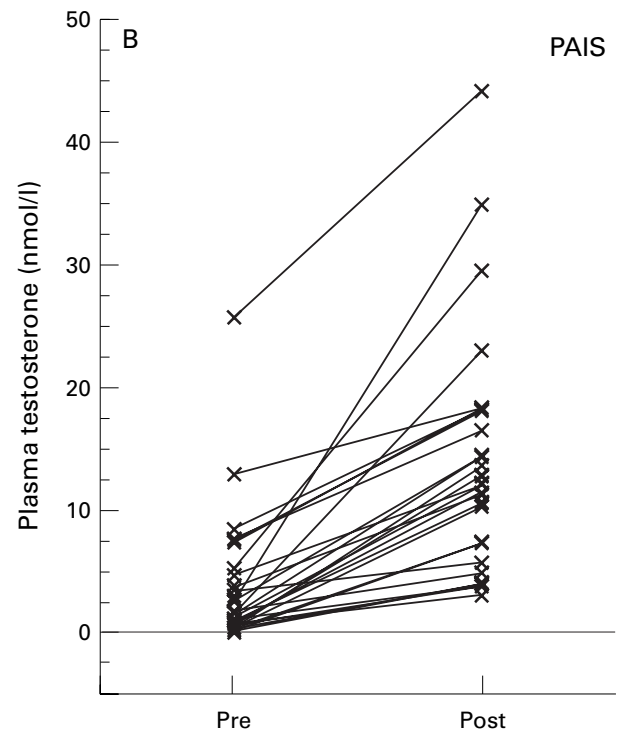

Figure 4 Increment in baseline plasma testosterone values (pre) following hCG stimulation (post) in AR +ve cases of complete AIS (CAIS) and partial AIS (PAIS). 

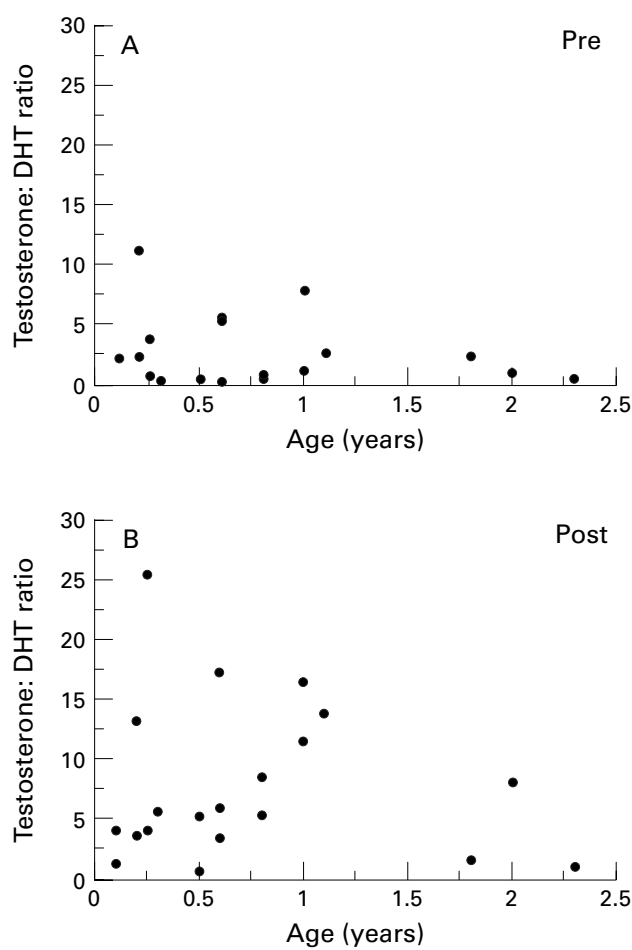

Figure 5 Plasma T:DHT ratio in children less than 3 years of age before (pre) and after (post) hCG stimulation.

analysed biochemical data collected through the UK ambiguous genitalia and intersex database on cases proved to have AR dysfunction because of abnormal AR binding and/or AR gene mutation. Because the molecular defect has the same basis, cases of complete AIS and partial AIS were studied as one group. The nature of the resource meant that there were no control data for each case, so we have relied on historical data gathered by Andersson et al and Winter et al. ${ }^{4-6}$ This reference range compares very well with that published by Forest et al. ${ }^{21} \mathrm{~A}$ register based study has the problem of data reporting from multiple and variable sources. Nevertheless, we believe this was more than offset by the large number of cases of AIS in which the tests had been performed and reported. Although assays were performed in a

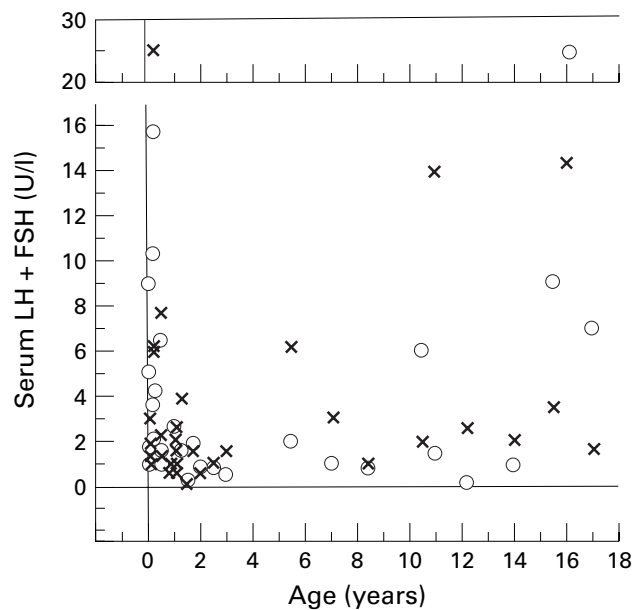

Figure 6 Basal serum LH and FSH concentrations in all AR +ve cases of AIS. Very high concentrationss in two patients are plotted separately.
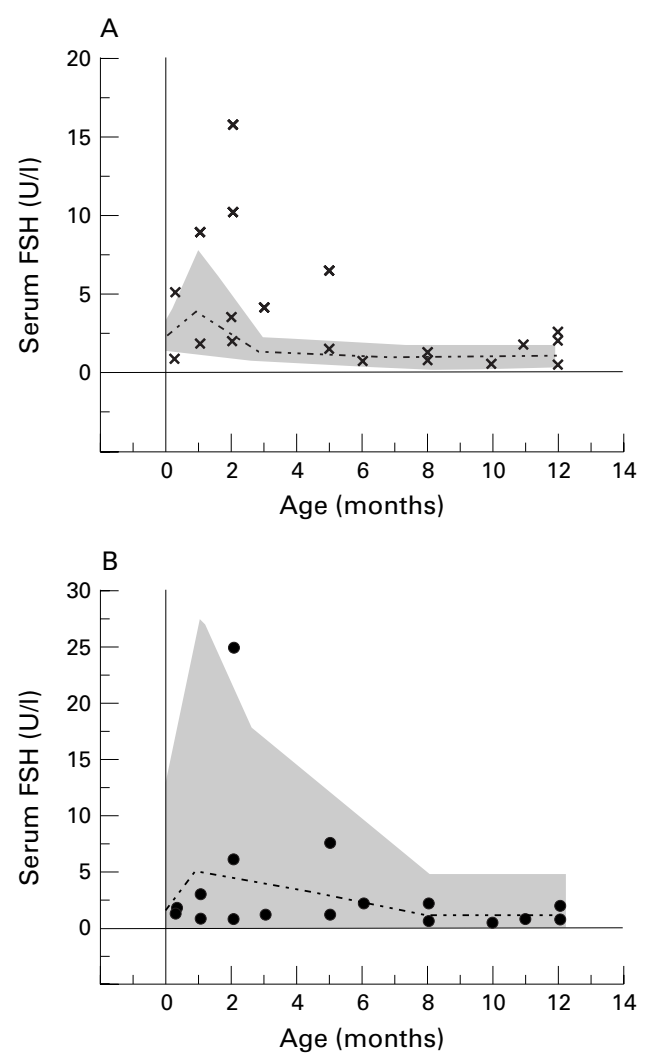

Figure 7 Basal LH and FSH concentrations in infants with AIS during the 1st year of life. The shaded area represents the normal reference range. ${ }^{4}$

number of laboratories, each was a participant in a national external quality control service.

There were a number of patients with suspected AIS in whom basal testosterone values and results of hCG stimulation tests were unavailable. The reason may just be incomplete data retrieval, but it is also possible that in some patients the tests were not performed. This occurred more often in complete AIS where the diagnosis seems to be more clear cut. However, confusion can occur with other causes of male undermasculinisation where the phenotype may be unambiguously female such as in Leydig cell hypoplasia, $5 \alpha$-reductase deficiency, and $17 \beta$ hydroxysteroid dehydrogenase deficiency.

The analysis indicates that hCG and LHRH stimulation tests as well as measurement of basal concentration of gonadotrophins and testosterone are performed often but not always in suspected cases of AIS. The dose of hCG varied considerably between and within centres; similar information about the LHRH stimulation test was not available. A single dose of hCG can sufficiently stimulate testosterone production in most cases ${ }^{22}$ and there is a need to standardise this test. However, the lack of a relation between total hCG dose and testosterone increment suggests that the dose is probably not that crucial; this method of analysis does not take account of the influence of repetitive stimulation delivered by multiple hCG injections.

During childhood, testosterone was mostly within normal reference ranges. The concentrations were abnormally high in some cases at 
Table 1 Median (range) basal and peak serum LH and FSH concentrations in cases with $A R / A B+v e A I S$ who had an LHRH stimulation test

\begin{tabular}{llll}
\hline & Infants $(n=10)$ & Children $(n=6)$ & Postpubertal $(n=9)$ \\
\hline LH(U/1) & $1.9(0.8-15.8)$ & $1.1(0.2-6.0)$ & $9.0(0.9-28.3)$ \\
Peak LH(U/1) & $13.5(4.5-50.0)$ & $6.6(3.0-35.0)$ & $41.9(7.2-77.9)$ \\
FSH(U/l) & $1.6(0.6-25.0)$ & $1.6(0.2-14.0)$ & $8.9(1.7-29.7)$ \\
Peak FSH(U/1) & $11.3(2.2-32.0)$ & $2.4(0.2-7.3)$ & $10.5(4.3-31.7)$ \\
\hline
\end{tabular}

the time of the postnatal surge, a phenomenon observed in normal boys between 2 and 6 months of age. ${ }^{5}$ The magnitude of this surge is highly variable in normals, as was seen in those with AIS in our study. Normally, sex hormone binding globulin (SHBG) concentrations show a parallel rise with testosterone during the surge of early infancy and the ratio of testosterone to SHBG, the free androgen index, does not change remarkably. ${ }^{23}$ However, administration of exogenous testosterone results in a fall in SHBG concentrations ${ }^{24}$ and this response has been shown to be absent in patients with AIS. ${ }^{25}{ }^{26}$ It is possible that changes in the free androgen index during the postnatal surge in testosterone have a characteristic pattern in AIS. Salivary testosterone concentrations, which reflect the non-protein bound fractions of total testosterone, ${ }^{27}$ might prove to be a noninvasive method of assessing these changes. Serum testosterone concentrations increased in all cases following hCG stimulation, although the increment was variable. In general, at least a twofold to threefold increase in testosterone is considered to be normal ${ }^{1328}$; a number of children in our study, with proved AR dysfunction, had a testosterone increment less than twofold. An inadequate rise in testosterone on hCG stimulation in patients with male under-masculinisation suggests a defect of testosterone biosynthesis; our study indicates that in such cases AR abnormalities still need to be considered. Previous studies suggest that the SHBG decrement following hCG stimulation should be insignificant in those cases where there is only a minimal rise in testosterone. ${ }^{25}$ An additional marker following hCG stimulation tests in cases of male under-masculinisation is an evaluation of phallic growth as a clinical index of androgen responsiveness. $^{29}$

The plasma testosterone response to hCG stimulation has been reported to be lower in cryptorchid boys compared with normal boys. ${ }^{12}$ We found no difference in response between children with bilateral scrotal and bilateral abdominal testes. No instances of testicular dysgenesis were reported in cases where testicular histology was performed (data not shown). The lower response in previous studies probably reflects the existence of a primary testicular abnormality underlying the cryptorchidism.

Baseline and post-hCG measurements of DHT were not often performed. The baseline $\mathrm{T}: \mathrm{DHT}$ ratio in patients in whom these measurements were performed was within the range 1.5-17 reported in normal male infants by Pang et $a l^{30}$ Our finding of a significant increase in the ratio following hCG stimulation does not concur with their observations in

\section{Key messages}

- Androgen insensitivity syndrome (AIS) is the largest single entity that leads to male under-masculinisation

- The diagnosis of AIS requires thorough exclusion of defects of testosterone biosynthesis and metabolism

- The hypothalamo-pituitary-gonadal axis is intrinsically active during the $1 \mathrm{st}$ month of life and this is an opportune time to investigate affected children

- Although adequate serum concentrations of testosterone exclude a defect in testosterone biosynthesis, a low testosterone value at baseline or following human chorionic gonadotrophin stimulation does not always exclude AIS

- Baseline luteinising hormone concentrations are not necessarily inappropriately high in AIS; a luteinising hormone releasing hormone stimulation test might be a useful investigation in later childhood

healthy infants, whereas the values were similar to those reported in healthy infants by Forest $e t$ al, which ranged between 6 and 16.8. ${ }^{21}$ An increase in the T:DHT ratio with age in this group of patients with AIS suggests an age dependent decrease in 5 5 -reductase activity, similar to that reported for normal children. ${ }^{30}$ One neonate with a clinical phenotype consistent with complete AIS and defective androgen binding had a T:DHT ratio of 25.8. This might be an example of AIS with a secondary $5 \alpha$-reductase deficiency, ${ }^{31}$ but the precise diagnosis awaits mutational analysis of the genes encoding both $5 \alpha$-reductase and AR. Our findings also suggest that the post-hCG stimulation T:DHT ratio may overlap with values expected in cases of $5 \alpha$-reductase deficiency, resulting in the likelihood of false positive cases. It is possible that the measurement of the urinary tetrahydrocortisol:allotetrahydrocortisol ratio might be a more specific indicator of $5 \alpha-$ reductase deficiency than the T:DHT ratio. ${ }^{32}$

Basal LH but not FSH values were often above the historical reference range and the pattern of variation was similar to that seen for testosterone. In a number of cases, however, LH was not greatly raised, indicating that a high basal LH value is not a universal finding in AIS. The surge in LH, which is also described in healthy infants, ${ }^{5}$ was accompanied during the first year by an exaggerated LH rise following LHRH stimulation. There was also an exaggerated FSH response in infancy but, unlike LH, this was not sustained in later childhood. These data support a direct role for androgen in controlling LH release. ${ }^{33-35}$

Our study provides data to help with the interpretation of investigations performed to evaluate the gonadotrophin-gonadal axis in cases of suspected AIS. Although a positive hCG stimulation test excludes biosynthetic defects of testosterone, an inadequate testosterone 
response does not necessarily exclude AIS. Basal $\mathrm{LH}$ and testosterone values are highly variable and might not be increased during early infancy. An LHRH stimulation test might be useful to evaluate cases of suspected AIS presenting in mid-childhood. Evaluation of the pituitarygonadal axis in the under-masculinised child using uniform protocols should be more routine if the diagnostic yield in AIS and related phenotypes is to be improved.

The support of numerous clinicians in the UK and the European mainland who have contributed cases to the database is gratefully appreciated. We thank Mrs $\mathrm{N}$ Coggins for maintaining the database, and L Dovey, Z Rasekh, and J Rowland for technical assistance. Currently, SFA has support from the Sir Halley Stewart trust. Grant support was received from the Birth Defects Foundation and the European Union Biomed the Birth Defects Foundation and the European Union Biomed programme, the Medical Research Council, and the Wellcome
Trust. Presented in part at the 25 th annual meeting of the British Society of Paediatric Endocrinology and Diabetes at the Royal Society of Medicine, London, UK.

1 Hughes IA, Williams DM, Batch JA, Patterson MN. Male pseudohermaphroditism: clinical management, diagnosis pseudohermaphroditism: clinical managem

2 Berkovitz GD, Lee PA, Brown TR, Migeon CJ. Etiologic evaluation of male pseudohermaphroditism in infancy and childhood. Am 7 D is Child 1984:138:775.

3 Viner RM, Teoh Y, Williams DM, Patterson MN, Hughes IA. Androgen insenstivity syndrome: a survey of diagnostic procedures and management in the UK. Arch Dis Child 1997;77:305-9.

4 Andersson A-M, Toppari J, Haavisto A-M, et al. Longitudinal reproductive hormone profiles in infants: peak of inhibin B levels in infant boys exceeds levels in adult men. 7 Clin Endocrinol Metab 1998;83:675-81.

5 Winter JSD, Faiman C, Hobson WC, Prasad AV, Reyes FI. Pituitary-gonadal relations in infancy: 1. Patterns of serum gonadotrophin concentrations from birth to four years of age in man and chimpanzee. $\mathcal{F}$ Clin Endocrinol Metab 1975 ; 40:545-51.

6 Winter JSD, Hughes IA, Reyes FI, Faiman C. Pituitarygonadal relations in infancy: 2. Patterns of serum gonadal steroid concentrations in man from birth to two years of steroid concentrations in man from birth to

7 Morris JM, Mahesh VB. Further observations on the syndrome, "testicular feminisation". Am $\mathcal{F}$ Obstet Gynecol 1963;87:731-48.

8 Tremblay RR, Foley TP, Corvol P, et al. Plasma concentration of testosterone, dihydrotestosterone, testosteroneoestradiol binding globulin, and pituitary gonadotrophins in the syndrome of male pseudohermaphroditism with testicular feminisation. Acta Endocrinol 1972;70:331-41.

9 Lee PA, Brown TR, LaTorre HA. Diagnosis of the partial androgen insensitivity chorionic-gonadotrophin stimulation tests in prepubertal and early pubertal boys. Eur $\mathcal{F}$ Paediatr 1986;154:890-2.

10 Nagel RA, Lippe BM, Griffin JE. Androgen resistance in the neonate: use of hormones of the hypothalamic-pituitarygonadal axis for diagnosis. $\mathcal{F}$ Pediatr 1986;109:486-8.

11 Isurugi $\mathrm{K}$, Hasegawa $\mathrm{F}$, Shibahara $\mathrm{N}$, et al. Incomplete testicular feminisation syndrome - studies on androgen receptor (AR) function, AR gene analysis, and aromatase activitor (AR) function, AR gene analysis, and aromatase activities at puberty and long-term observations of clinical and
hormonal features from infancy to puberty. Endocr $\mathcal{7} 1996$; hormonal fe

12 Grant DB, Laurance BM, Atherden SM, Ryness J. HCG stimulation test in children with abnormal sexual development. Arch Dis Child 1976;51:596-601.

13 Davenport M, Brain C, Vandenberg C, et al. The use of the HCG stimulation test in the endocrine evaluation of cryptorchidism. Br f Urol 1995;76:790-4.

14 Urban MD, Lee PA, Lanes R, Migeon CJ. HCG stimulation test in children with cryptorchidism. Clin Pediatr 1986;26: $512-14$
15 Balducci R, Ghirri P, Brown TR, et al. A clinician looks at androgen resistance. Steroids 1996;61:205-11.

16 Rosenfeld RL, Barmach de Niepomniszsze, Kenney FM, Genel M. The response to human chorionic gonadotrophin administration in boys with and without $\Delta^{5}-3 \beta-$ hydroxysteroid dehydrogenase deficiency. $\mathcal{F}$ Clin Endocrinol Metab 1974;39:370-4.

17 Batch JA, Williams DM, Davies HR, et al. Androgen receptor gene mutations identified by SSCP in fourteen subjects with androgen insensitivity syndrome. Hum Mol Genet 1992;1:497-503.

18 Hughes IA, Evans BAJ. The fibroblast as a model for androgen resistant states. Clin Endocrinol 1988;28:565-9.

19 Quigley CA, De Bellis A, Marschke KB, El-Awady MK, Wilson EM, French FS. Androgen receptor defects: historical, clinical, and molecular perspectives. Endocr Rev 1995;16:271-321.

20 Forest MG, Mollard P, David M, Morel Y, Bertrand J. Syndrome d'insensibilite incomplete aux androgenes. Arch Fr Paediatr 1990;47:107-13.

21 Forest MG, De Peveretti E, Bertrand J. Testicular and adrenal androgens and their binding to plasma proteins in the perinatal period: developmental patterns of plasma testosterone, 4-androstenedione, dehydroepiandrosterone and its sulfate in premature and small for date infants as compared with that of full term infants. F Steroid Biochem 1980; 12:25-36

22 Kauchansky A, Frydman M, Nussinovitch M, Varsano I. Evaluation of human chorionic-gonadotrophin stimulation tests in prepubertal and early pubertal boys. Eur $\mathcal{F}$ Paediatr 1995;154:890-2.

23 Bolton NJ, Tapanainen J, Koivisto M, Vihko R. Circulating sex hormone binding globulin and testosterone in newborns and infants. Clin Endocrinol 1989;31:201-7.

24 Belgoroski A, Rivarola MA. Sex-hormone binding globulin response to testosterone. An androgen sensitivity test. Acta Endocrinol 1985;109:130-8.

25 Bertelloni S, Federico G, Baroncelli GI, et al. Biochemical selection of prepubertal patients with androgen insensitivity syndrome by sex hormone-binding globulin response to the human chorionic gonadotrophin test. Pediatr Res 1997; 41:266-71.

26 Sinnecker GHG, Hiort O, Nitsche PM, Kruse K. Functional assessment and clinical classification of androgen sensitivity in patients with mutations of androgen receptor sensitivity in patients with mutation
gene. Eur f Pediatr 1995;156:7-14.

27 Huhtaniemi I, Dunkel L, Perheentupa J. Transient increase in postnatal testicular activity is not revealed by longitudinal measurements of salivary testosterone. Pediatr Res 1986;20:1324-7.

28 Walker JM, Hughes IA. Tests and normal values in paediatric endocrinology. In: Brook CGD, ed. Clinical paediatric endocrinology. Oxford: Blackwell Science Ltd, 1995:782.

29 Almaguer MC, Saenger P, Linder BL. Phallic growth after HCG - a clinical index of androgen responsiveness. Clin Pediatr 1993;32:329-33.

30 Pang S, Levine LS, Chow D, Sagian F, Saenger P, New MI. Dihydrotestosterone and its relationship to testosterone in infancy and childhood. 7 Clin Endocrinol Metab 1985;48: infancy

31 Imperato-McGinley J, Peterson RE, Gautier $\mathrm{T}$, et al. Hormonal evaluation of a large kindred with complete androgen insensitivity: evidence for secondary $5 \alpha-$ reductase deficiency. F Clin Endocrinol Metab 1982;54:93141.

32 Odame I, Donaldson MDC, Wallace AM, Cochran M, Smith PJ. Early diagnosis and management of 5-alphareductase deficiency. Arch Dis Child 1992;67:720-3.

33 Bagatell CJ, Dahl KD, Bremner WJ. The direct pituitary effect of testosterone to inhibit gonadotropin secretion in men is partially mediated by aromatization to estradiol. $\mathcal{f}$ Androl 1994;15:15-21.

34 Shecker CB, Matsumoto AM, Bremner WJ. Testosterone administration inhibits gonadotropin secretion by an effect directly on the human pituitary. F Clin Endocrinol Metab 1989;68:397-401

35 Zarate A, Canales SE, Soria J, Carballo O. Studies on the luteinizing hormone and follicle-stimulating hormonereleasing mechanism in the testicular feminization syndrome. Am f Obstet Gynecol 1974;119:971-7. 